\title{
Laboratory-Acquired Dengue Virus Infection, United States, 2018
}

\author{
Tyler M. Sharp, Teresa G. Fisher, Kristin Long, Garry Coulson, Freddy A. Medina, Carolyn Herzig, \\ Mary Beth Koza, Jorge Muñoz-Jordán, Gabriela Paz-Bailey, Zack Moore, Carl Williams
}

Investigation of a dengue case in a laboratory worker in North Carolina, USA, revealed that the case-patient prepared high-titer dengue virus stocks soon before illness onset. Improper doffing of gloves with an open finger wound likely resulted in cutaneous exposure. This case reinforces recommendations for enhanced precautions when working with high-titer dengue virus.

Tour genetically distinct but serologically related den1 gue viruses (DENV-1-4) cause dengue, an acute febrile illness common throughout the tropics (1). DENV is transmitted by Aedes mosquitoes and has a median incubation period of 6 days (2). Other routes of DENV transmission include perinatal (3), blood transfusion (4), needle stick (5), and laboratory exposure (6-8).

In August 2018, the North Carolina Department of Health and Human Services (NCDHHS; Raleigh, North Carolina, USA) was notified of a dengue case in a laboratory worker. NCDHHS and CDC conducted an investigation to identify the most likely route of exposure.

\section{The Study}

We interviewed the case-patient and reviewed medical records to collect travel history, potential exposures, clinical course, and diagnostic test results. The case-patient reported no recent travel to an area with ongoing DENV transmission. No travel-associated dengue cases were reported in 2018 from the county where the case-patient worked and resided. The

Author affiliations: US Public Health Service, Rockville, Maryland, USA (T.M. Sharp); Centers for Disease Control and Prevention,

San Juan, Puerto Rico, USA (T.M. Sharp, F.A. Medina, J. Jorge Muñoz-Jordán, G. Paz-Bailey); North Carolina Department of Health and Human Services, Raleigh, North Carolina, USA

(T.G. Fisher, K. Long, C. Herzig, Z. Moore, C. Williams); University of North Carolina at Chapel Hill, Chapel Hill, North Carolina, USA

(G. Coulson, M.B. Koza); Centers for Disease Control and

Prevention, Atlanta, Georgia, USA (C. Herzig)

DOI: https://doi.org/10.3201/eid2607.191598 case-patient reported illness onset on July 18, 2018, with retroorbital eye pain, fever, myalgia, arthralgia, lethargy, chills, and lymphadenopathy (Figure 1 ). By July 23, the case-patient was afebrile but had a whole-body maculopapular rash. The case-patient was evaluated by a physician that day and received a diagnosis of viral illness. After reporting the illness to the institutional occupational health clinic, the case-patient was referred to an infectious disease physician. Upon evaluation 2 days later, vital signs and laboratory values were unremarkable except for leukopenia $\left(3.3 \times 10^{6}\right.$ cells $\left./ \mathrm{mm}^{3}\right)$.

Four serum specimens were forwarded to CDC for diagnostic testing: a baseline specimen collected $\approx 1.5$ years before illness onset; an acute specimen collected 7 days after illness onset; an early-convalescent specimen collected $\approx 1$ month after illness onset; and a late-convalescent specimen collected $\approx 6$ months after illness onset (Table). The acute specimen tested positive at a commercial laboratory for detection of nonstructural protein 1 (NS1) antigen and DENV IgM and negative for Ehrlichia IgG. At CDC, reverse transcription PCR (9) performed on the acute specimen was negative; DENV IgM and IgG were detected $(10,11)$ in acute and convalescent specimens. In the baseline specimen, neutralizing antibodies were detected for yellow fever virus but not DENV or West Nile virus. Comparison of DENV neutralizing antibody titers in acute, early convalescent, and late convalescent serum specimens confirmed incident DENV infection; however, a $\geq 4$-fold rise in neutralizing antibody titer against multiple DENVs precluded identification of the specific infecting DENV.

We visited the research laboratory where the case-patient worked; the principal investigator and laboratory safety officer described laboratory safety protocols. We reviewed laboratory activities performed by the case-patient in the week before illness onset and interviewed the case-patient regarding practices of donning and doffing personal protective equipment (PPE). 


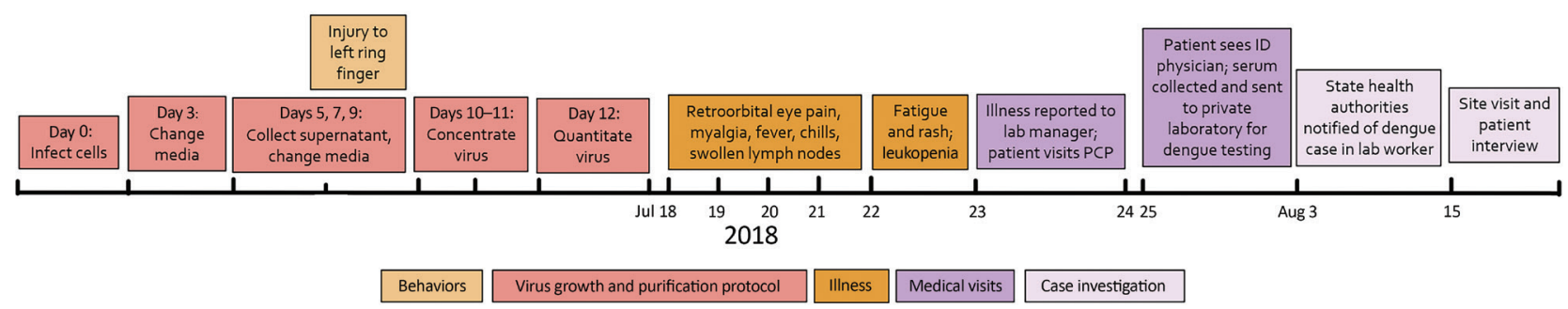

Figure 1. Timeline of events surrounding a case of laboratory-acquired dengue virus infection, United States, 2018. ID, infectious disease; PCP, primary care physician.

In the 2 weeks before illness onset, the casepatient reported working with a protocol to grow, purify, and concentrate DENV-4. The case-patient reported wearing a single pair of nitrile gloves, eye protection, a lab coat, and closed-toed shoes while working with infectious virus in a certified biosafety cabinet (BSC).

The protocol for virus production and concentration included inoculating $\approx 40$ roller bottles of Vero cells with $\approx 10^{6}$ plaque-forming units (PFU) of DENV4 (Figure 1). Media were harvested and pooled on days 5,7 , and 9 postinoculation and concentrated by tangential flow filtration followed by sucrose gradient fractionation. Fractions were collected by piercing the centrifugation tubes and collecting fractions using a safety mechanism that prevented needle sticks. Fractions were separated by sodium dodecyl sulfate polyacrylamide gel electrophoresis and protein concentration determined using a bicinchoninic acid assay. Typical protein concentrations correlated with virus titers of $10^{9}-10^{10} \mathrm{PFU} / \mathrm{mL}$. The case-patient also performed neutralization and ELISA assays for DENV-1-4 during the 2 weeks before illness onset.

The case-patient reported that small splashes often occurred during virus production and purification. The case-patient did not change gloves when splashes occurred but occasionally performed surface decontamination of gloves and the BSC with $70 \%$ ethanol. The case-patient estimated entering and exiting the BSC 6-8 times per day on most days of the protocol but not being vigilant about handwashing after removing gloves. The case-patient reported taking online Biosafety Level 2 (BSL-2) training upon joining the laboratory, receiving hands-on training for BSL-2 work, and annually reviewing laboratory safety plans and procedures.

The case-patient reported having sustained a compression wound on the ring finger of the left hand on July 9 or 10; the wound later appeared infected and oozing. The case-patient reported not bandaging or covering this wound before donning a single pair of gloves while working on the protocol for virus production and purification. The case-patient demonstrated their technique for doffing gloves (Figure 2): the base of the glove of the left hand was pinched with the thumb and forefinger of the right hand and the glove removed while turning it inside out, after which the base of the glove on the right hand was pinched with the thumb and forefinger of the now ungloved left hand. The case-patient acknowledged that the wound on the ring finger of the left hand could have contacted the potentially contaminated glove on the right hand. The case-patient also mentioned having potentially touched mucosal surfaces of the nose or mouth with the lab coat sleeve while working with infectious virus in the BSC.

\section{Conclusions}

The presence of an open finger wound during work with high-titer DENV coupled with improper glove

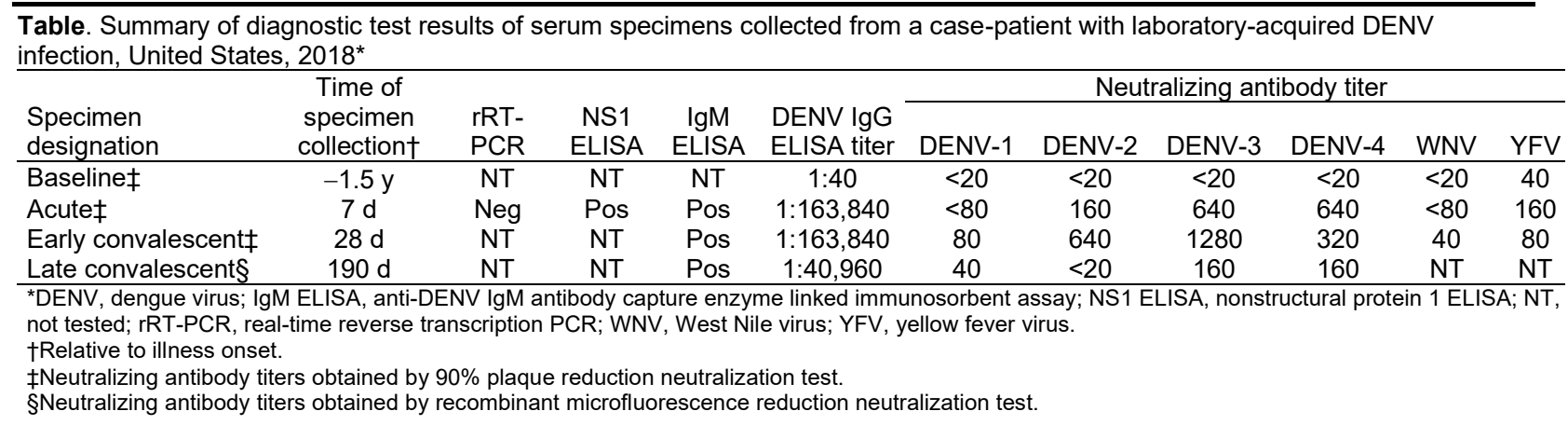




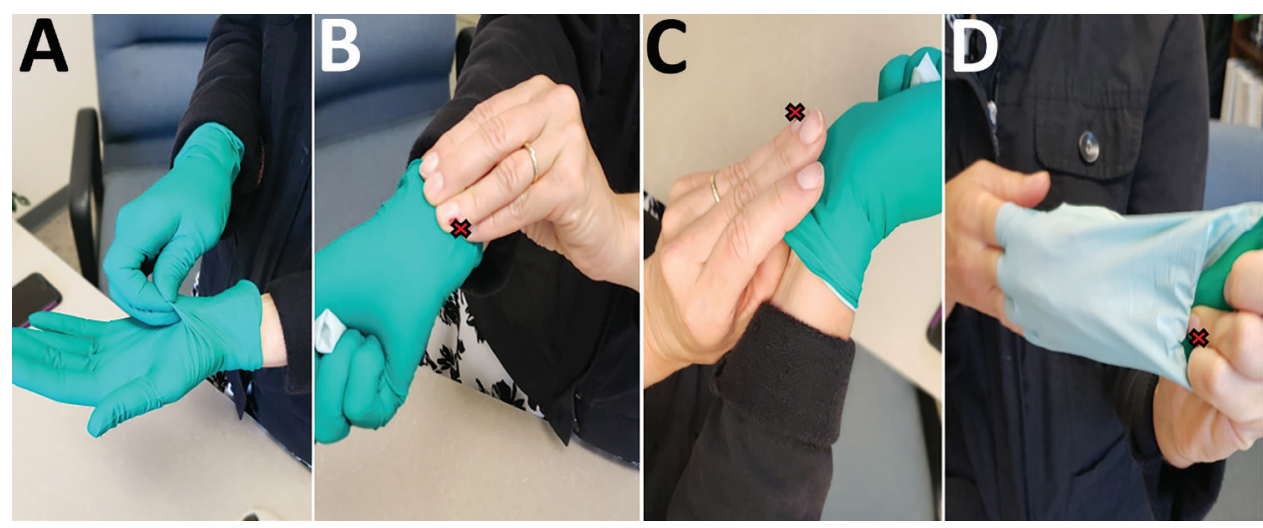

Figure 2. Depiction of improper protocol for doffing gloves the case-patient reported using while conducting a protocol for growth and purification of hightiter dengue virus, United States, 2018. The red $X$ indicates the location of an open wound on the ring finger of the casepatient's left hand.

doffing suggests that laboratory-acquired infection by cutaneous exposure was the most likely route of DENV infection in this case. However, other routes of exposure, including mucosal, could not be ruled out.

Three previous cases of laboratory-associated DENV infection have been reported. In Nigeria, a laboratorian responsible for cleaning cages and disposing of mice infected with DENV-1 became infected, although mosquito-borne transmission could not be ruled out (6). A laboratorian in Australia was infected while working with DENV-2 (7), although it could not be determined if infection occurred from a bite from an infected mosquito in the laboratory or potential mucocutaneous exposure while working with infectious virus. In South Korea, a laboratorian was infected with DENV-2 following a needle stick injury while filtering cell cultures of DENV-2 (8).

In this case, detection of NS1 antigen independently confirmed acute DENV infection, supported by detection of DENV IgM and >4-fold rise in DENV IgG and DENV neutralizing antibody. However, historic exposure to $\geq 1$ flavivirus complicated interpretation of neutralizing antibody titers and precluded identification of the infecting DENV. Moreover, we could not rule out infection with DENV between collection of the baseline and acute specimens. The difficulty interpreting flavivirus neutralizing antibody patterns during secondary infections is well described (12).

A study in Belgium conducted during 2007-2012 found that only $40 \%$ of laboratory-associated infections occurred following a known exposure event; a definitive cause of exposure could not be identified in nearly one third of cases associated with bloodborne pathogens (13). Thus, laboratory-acquired infections, including those with DENV, likely occur more frequently than have been documented.

Titers of infectious DENV in human blood resulting from mosquito-borne transmission are typically $10^{3}-10^{7}$ $\mathrm{PFU} / \mathrm{mL}$ (14). At $10^{9}-10^{10} \mathrm{PFU} / \mathrm{mL}$, the concentration of DENV the case-patient handled would have been 100 to 10 million times higher than the concentration found in the average blood specimen of a patient with DENV infection. Although BSL-2 containment is recommended for laboratory work with DENV, enhanced safety precautions including double-gloving are recommended when handling large-scale or high-titer virus (15). This investigation highlights the importance of developing and maintaining risk assessment and management programs to mitigate exposures to infectious agents and emphasizing good microbiological practices and procedures training for laboratorians, including proper PPE donning and doffing techniques.

\section{Acknowledgments}

We thank the case-patient, laboratory director, and laboratory safety manager for their support of this investigation. We also thank North Carolina State Laboratory of Public Health Special Serology staff for assistance with transport of specimens to CDC for diagnostic testing.

Financial support for this investigation was provided by NCDHHS and CDC.

\section{About the Author}

Dr. Sharp is a health scientist in the National Center for Emerging and Zoonotic Infectious Diseases, the Centers for Disease Control and Prevention, San Juan, Puerto Rico, USA. His public health and research interests are the epidemiology and pathophysiology of emerging tropical infectious diseases.

\section{References}

1. Simmons CP, Farrar JJ, van Vinh Chau N, Wills B. Dengue. N Engl J Med. 2012;366:1423-32. https:/ / doi.org/10.1056/ NEJMra1110265

2. Chan M, Johansson MA. The incubation periods of dengue viruses. PLoS One. 2012;7:e50972. https:/ / doi.org/10.1371/ journal.pone.0050972 
3. Sirinavin $S$, Nuntnarumit $P$, Supapannachart $S$, Boonkasidecha S, Techasaensiri C, Yoksarn S. Vertical dengue infection: case reports and review. Pediatr Infect Dis J. 2004;23:1042-7. https:/ / doi.org/10.1097/ 01.inf.0000143644.95692.0e

4. Tomashek KM, Margolis HS. Dengue: a potential transfusion-transmitted disease. Transfusion. 2011;51:165460. https://doi.org/10.1111/j.1537-2995.2011.03269.x

5. Ohnishi K. Needle-stick dengue virus infection in a health-care worker at a Japanese hospital. J Occup Health. 2015;57:482-3. https://doi.org/10.1539/joh.14-0224-CS

6. Tomori $\mathrm{O}$, Monath TP, $\mathrm{O}^{\prime}$ Connor EH, Lee VH, Cropp CB. Arbovirus infections among laboratory personnel in Ibadan, Nigeria. Am J Trop Med Hyg. 1981;30:855-61. https://doi.org/10.4269/ajtmh.1981.30.855

7. Britton S, van den Hurk AF, Simmons RJ, Pyke AT, Northill JA, McCarthy J, et al. Laboratory-acquired dengue virus infection - a case report. PLoS Negl Trop Dis. 2011;5:e1324. https:/ / doi.org/10.1371/ journal.pntd.0001324.

8. Lee C, Jang EJ, Kwon D, Choi H, Park JW, Bae GR. Laboratory-acquired dengue virus infection by needlestick injury: a case report, South Korea, 2014. Ann Occup Environ Med. 2016;28:16. https:/ / doi.org/10.1186/ s40557-016-0104-5

9. Santiago GA, Vazquez J, Courtney S, Matias KY, Andersen LE, Colon C, et al. Performance of the Trioplex real-time RT-PCR assay for detection of Zika, dengue, and chikungunya viruses. Nat Comm. 2018;9:1391. https:/ / doi.org/10.1038/s41467-018-03772-1
10. Johnson AJ, Martin DA, Karabatsos N, Roehrig JT. Detection of anti-arboviral immunoglobulin $\mathrm{G}$ by using a monoclonal antibody-based capture enzyme-linked immunosorbent assay. J Clin Microbiol. 2000;38:1827-31.

11. Martin DA, Muth DA, Brown T, Johnson AJ, Karabatsos N, Roehrig JT. Standardization of immunoglobulin M capture enzyme-linked immunosorbent assays for routine diagnosis of arboviral infections. J Clin Microbiol. 2000;38:1823-6.

12. Calisher $\mathrm{CH}$, Karabatsos N, Dalrymple JM, Shope RE, Porterfield JS, Westaway EG, et al. Antigenic relationships between flaviviruses as determined by cross-neutralization tests with polyclonal antisera. J Gen Virol. 1989;70:37-43. http:/ / dx.doi.org/10.1099/0022-1317-70-1-37

13. Willemarck NAJ, Van Vaerenbergh B, Descamps E, Brosius B, Dai Do Thi C, Amaya L, et al. Laboratory-acquired infections in Belgium (2007-2012). Brussels: Institut Scientifique de Sante Publique; 2015.

14. Moi ML, Lim CK, Kotaki A, Takasaki T, Kurane I. Detection of higher levels of dengue viremia using FcyR-expressing BHK-21 cells than Fc $\gamma$ R-negative cells in secondary infection but not in primary infection. J Infect Dis. 2011;203:1405-14. https://doi.org/10.1093/infdis/jir053

15. US Department of Health and Human Services. Biosafety in microbiological and biomedical laboratories, 5 th ed. Washington (DC): The Department; 2009.

Address for correspondence: Carl Williams, North Carolina Department of Health and Human Services, 1902 Mail Service Center, Raleigh, NC 27699-1902; email: carl.williams@dhhs.nc.gov
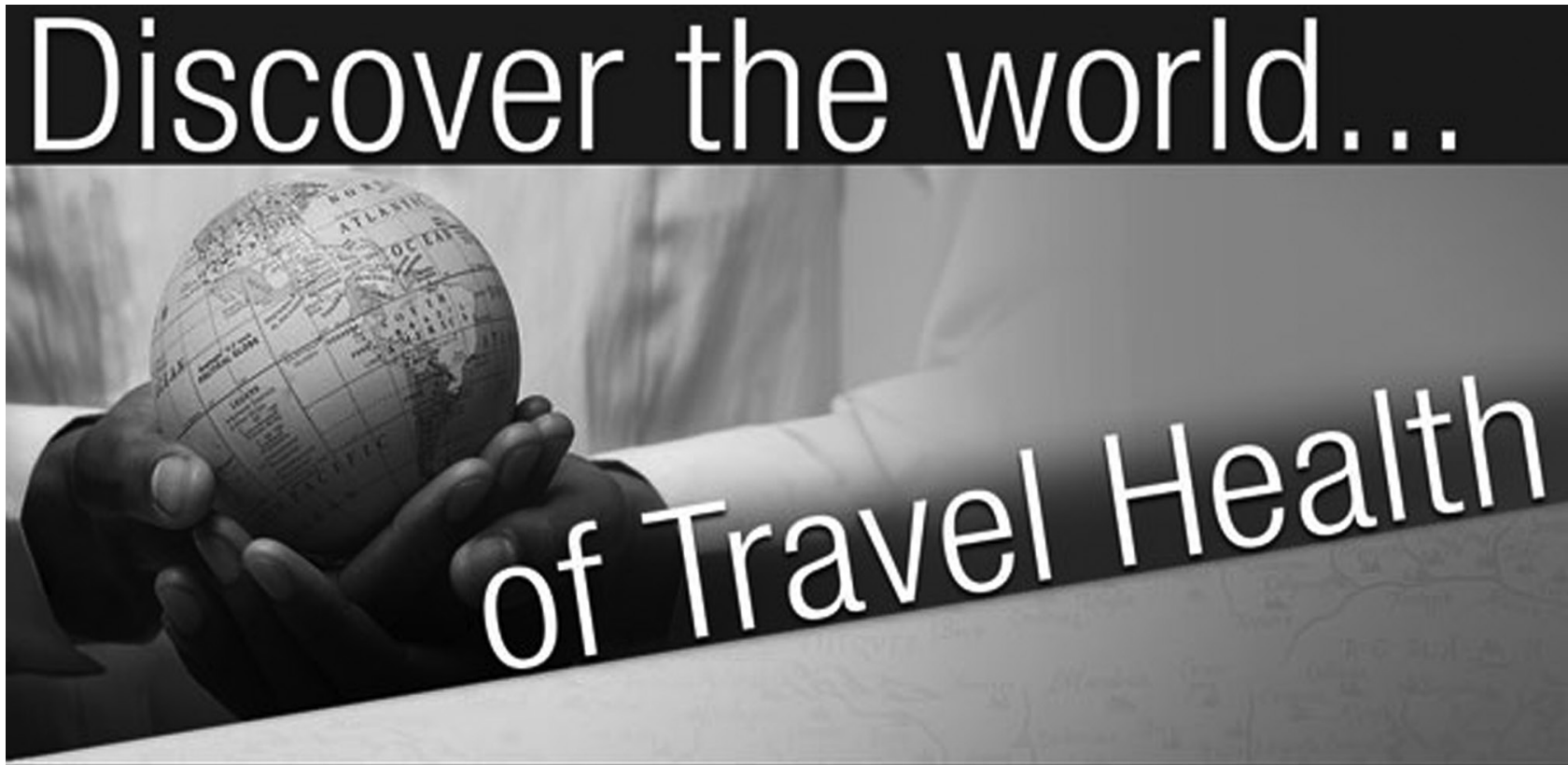

\section{www.cdc.gov/travel}

Visit the CDC Travelers' Health website for up-to-date information on global disease activity and international travel health recommendations. 